\title{
OS CAMINHOS DA PESQUISA EM POÉTICAS VISUAIS ATRAVÉS DE UMA PRÁTICA PESSOAL EM PINTURA
}

\section{Ricardo Perufo Mello}

\section{Resumo}

Este artigo propõe-se como uma reflexão a respeito, e a partir, das investigações que empreendi nos últimos dez anos, durante o período do Mestrado e do Doutorado em Artes Visuais, no estabelecimento de um processo pictórico que elaborei como artista/pesquisador na linha de Poéticas Visuais. O propósito deste texto é argumentar, valendo-se de uma experiência pessoal de investigação, o que caracteriza e constitui uma pesquisa em Poéticas Visuais. A premissa nesse percurso foi a de que uma pesquisa nesta linha deve contemplar os meandros de sua própria construção, concomitantemente a esse fazer. Ou seja, estudos e análises são guiados pelos desdobramentos do trabalho de ateliê e, simultaneamente, fornecem os parâmetros para a continuidade desse processo.

\section{Palavras-chave:}

Poéticas Visuais; Pintura; Arte Contemporânea; Poiética; Artista/Pesquisador.

No campo das Artes Visuais, a passagem histórica do século XIX para o século XX presenciou uma situação cada vez mais plena de liberdade do artista em termos de autonomia e inserção social. No decorrer do século XX - especialmente ao longo das décadas de 50 a 70 -, a figura do artista busca afirmar e construir gradual e fundamentalmente uma independência para si como cidadão e para a sua produção em termos autorais.

Tal condição foi alcançada não apenas no que diz respeito às temáticas que são abordadas pelos artistas, mas mesmo nas próprias estruturas do que compõe o objeto de arte e por quais meandros este se manifesta. Como é o caso de artistas relacionados ao movimento da Arte Conceitual, tais

\section{Abstract}

The main goal of this article is to present a reflection about my pictorial process as it was established from my condition of artist/researcher in the Visual Poetics line of research, during the course of my Master's and Doctorate's degrees in the last ten years. The purpose of this writing is to indicate what caracterize and constitute a Visual Poetics research, and that is done here through my personal investigation experience. The notion that this kind of research must encompass the intricacies of its own making was the premise of my investigations, as well as was the notion that these investigations should be consider as a guidance to the artistic making. Therefore the analyses and studies in this kind of research are determined by the unfolding of the work's process, at the same time that the theoretical development helps building this process of work.

\section{Keywords:}

Visual Poetics; Painting; Contemporary Art; Poietics; Artist/Researcher.

como Joseph Kosuth e os artistas pertencentes ao Grupo Fluxus, que definiram e estabeleceram para si estratégias de trabalho, produção e atuação que desmaterializavam o objeto de arte e prescindiam até mesmo do mercado de arte para existir e se manifestar, buscando outros modos de inserção e circulação (WOOD, 2002).

Joseph Beuys, artista relacionado ao Grupo Fluxus e aos seus modos de prática e existência, teve como parte importante e indissociável de seu trabalho de arte sua atuação como professor - seja por vias informais, como performances ou na academia de artes Kunstakademie Düsseldorf (entre 1961 e 1972). Beuys entendia mesmo que a prática pedagógica era um dos modos mais pertinentes de 


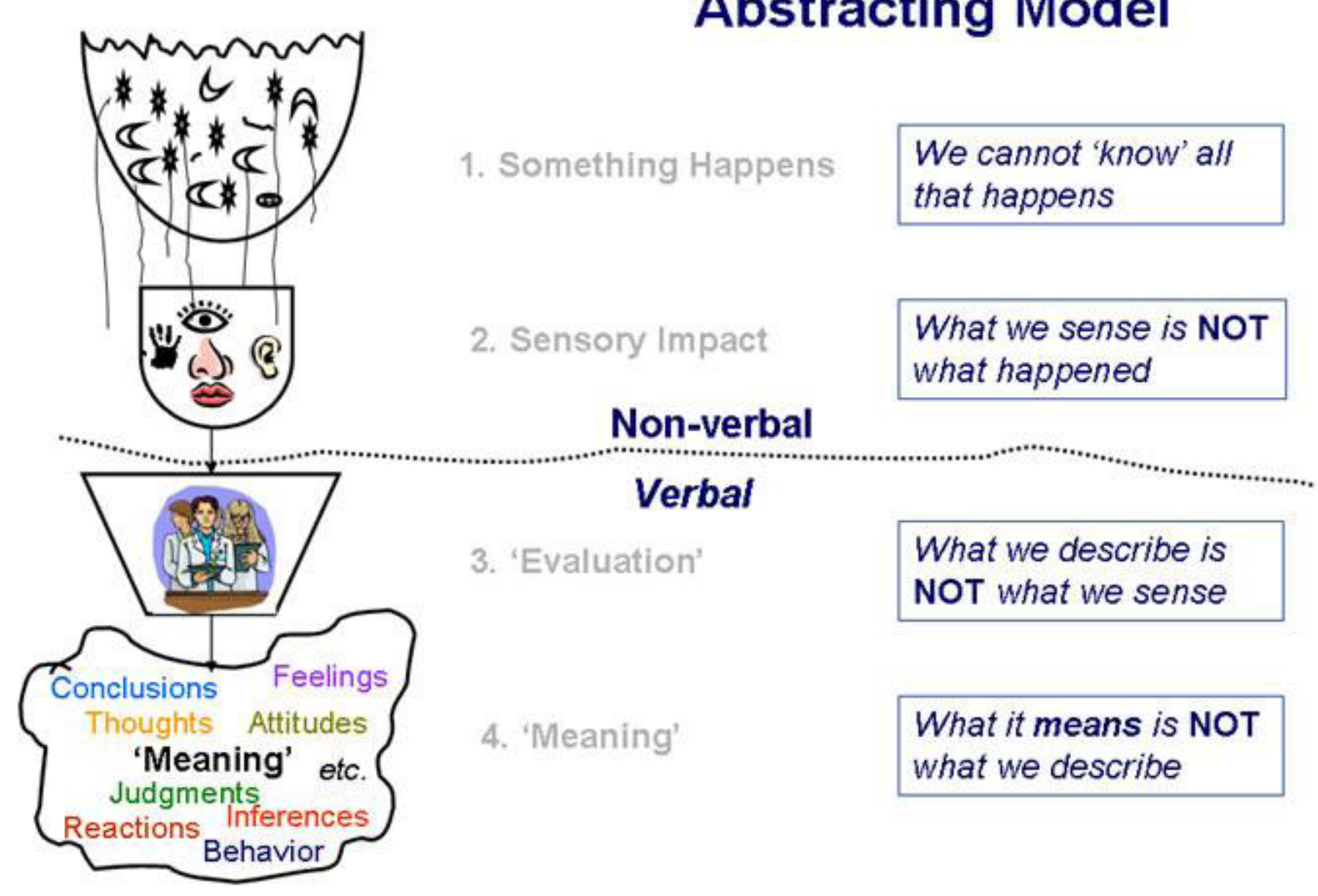

Abstracting Model

We cannot 'know' all that happens

What we sense is NOT

what happened

Figura 1 - Ed Atkins, "Sem Título", 2012 - publicado pelo artista no site http://atumour. tumblr.com/post/18326091308

manifestação da arte.

Também no Brasil compartilhamentos de trabalho e agrupamentos para ações foram relevantes para os desdobramentos da Arte ao longo de tais décadas. o Grupo Rex, formado pelos artistas Wesley Duke Lee, Geraldo de Barros e Nelson Leirner, realizou exposições, periódicos de arte independentes (o Rex Time), palestras, happenings e projeções de filmes entre 1966 e 1967. O grupo teve a participação também do professor da ECA/USP (Escola de Comunicação e Artes da Universidade de São Paulo) e artista Carlos Fajardo, que passou a lecionar nesta instituição a partir de 1996, tendo obtido o título de doutor em Poéticas Visuais em 1998. A artista brasileira Carla Zaccagnini, mestre em Poéticas Visuais também pela ECAUSP, observa nesse sentido que "a universidade proporciona ao artista um espaço para elaborar "um pensamento" ou "um discurso a respeito da produção"'" (RIBEIRO, s.d.).

A partir desses exemplos pontuais, entendo aqui que nesses vieses a universidade é igualmente para o artista um caminho possível instaurado ao longo das últimas décadas como estratégia para existir e para dar existência ao seu trabalho. Isto no sentido de criar, elaborar, refletir e manifestar essa produção, o que se dá através da linha de pesquisa que é identificada como Poéticas Visuais. Como analisa o professor Flávio Gonçalves do Programa de Pós Graduação em Artes Visuais da UFRGS, que trabalha nesta linha de pesquisa:

Um lugarnessas circunstâncias não é simplesmente "dado", mas é o resultado de concorrida disputa, o que acaba por desacomodar (ou incomodar) outras instâncias do saber. (...) Os artistas têm afluído aos cursos de pós-graduação em artes e mesmo que o significado dessa busca ultrapasse o objetivo deste texto, muitas são as críticas quanto ao modo de inserção (estratégias de adoção, impregnação, simbiose, camuflagem, negação, submissão, confronto etc.). (...) Antes de negá-la é preciso, diante de sua inevitável presença, enfrentar o desafio de pensá-la, a fim de identificar entre os acertos e equívocos um caminho que possa melhor acomodar a arte sem subjugá-la. (2009, p. 138, grifo do autor). 
Parto aqui deste entendimento quanto à pesquisa em Poéticas Visuais, sem deixar de observar as particularidades desta abordagem metodológica e acadêmica num processo que tem o inesperado, o sensível, o imprevisível e o imponderável em suas engrenagens de "funcionamento", pois envolve a criação artística. Para avançar na discussão e argumentação da pertinência em se constituir um processo de elaboração artística por meio das articulações próprias à uma pesquisa acadêmica, passo a expor algumas considerações e apontamentos a respeito de minha própria prática de pesquisa como artista e pintor na universidade ao longo dos últimos anos, na condição de "artista/pesquisador"1.

Na conjunção de elencar e definir conceitos com as atividades do trabalho de ateliê abracei a busca por alguma espécie de cientificidade (assumindo-se os paradoxos contidos nessa busca) durante o processo de criação de um trabalho em artes visuais. Assumir tais paradoxos de forma deliberada poderia ser interpretado como uma direção despropositada, ao levar-se em conta o quão inescrutável e imprevisível é a ação criadora. Contudo, tal pesquisa alinha-se com a postura de René Passeron, quando ele afirma que "reivindicamos a autonomia da poiética como reflexão sobre a conduta criadora" (2004, p. 10, grifo nosso).

Durante minhas pesquisas a noção de poiética foi instrumento teórico importante para a articulação entre a feitura prática e a reflexão textual. Segundo o autor, a poiética seria "a promoção filosófica das ciências da arte que se faz", entendendo-se poiética como "uma teoria filosófica da criação artística" (PASSERON apud GONÇALVES, 2009, p. 141142). De modo que a poiética tem como foco "o reconhecimento da criação artística como processo em si, dentro do escopo de uma ciência da arte que parece se esforçar para marcar sua diferença em relação à outras, sobretudo a Estética" (GONÇALVES, 2009, p. 142). Um conceito que "trata de elucidar, tanto quanto é possível fazê-lo, o fenômeno da criação (...) a poiética será o que fizermos dela, nos limites de seu alcance, com a certeza ambiciosa de chegar a alguma verdade em um domínio reputado obscuro" (PASSERON, 2004, p. 10).

Numa progressiva elaboração teórica e reflexiva em constante intercâmbio com o trabalho de ateliê a compreensão foi a de que essa é uma postura que edifica a pesquisa em Poéticas Visuais. Nesse sentido é necessário esclarecer que a posição e o olhar de pesquisador do artista que medita sobre sua produção prática simultaneamente a elaboração desta não é o mesmo daquele da pesquisa sobre arte, que se faz por um olhar outro que não o do artista (como é o caso no campo da Estética ou da História e Crítica de Arte, por exemplo).

Em outras palavras, o artista, ao se dispor a percorrer uma pesquisa em Poéticas Visuais, opera no "lado de dentro" das Artes Visuais, pelo interior do seu processo criativo e criador. Enquanto o historiador ou o crítico analisa o campo das Artes pelo "lado de fora", perscrutando as obras, situações e biografias dos artistas tão próxima e intimamente quanto possível, mas inevitavelmente através de um olhar e experiência alheios ao processo mesmo da criação artística.

Desta maneira, pode-se pensar a elaboração da pesquisa em Poéticas Visuais como algo semelhante à um caderno de apontamentos do artista ou um "diário de bordo". Isto é, um lugar onde ele compila suas coleções de achados, estudos sobre outros artistas ou passagens que considera relevante na História da Arte, referências à obras de outros artistas, considerações sobre seus possíveis acertos ou equívocos, rotas e desvios durante o que imaginou fazer em sua prática e o que acabou fazendo de fato - tudo isto ao longo de seu processo de criação naquele momento.

Muitos artistas empreenderam algo do tipo ao longo da História da Arte. Como exemplos pontuais que compilam diversas reflexões de artistas sobre seus próprios trabalhos, obras e processos, podemos citar o livro "Teorias da Arte Moderna" organizado por Herschel Chipp (1988), que apresenta textos de artistas pontuais de movimentos como Pós Impressionismo, Fauvismo, Cubismo, Construtivismo, Dada, Surrealismo. Também o livro "Art in theory, 1900-2000: an anthology of changing ideas" organizado por Paul Wood e Charles Harrison, que "mostram que a projeção modernista faliu também na divisão projetada entre o papel de artista e crítico, segundo a qual se supunha que "o artista fosse um 'fazedor desarticulado' em cujo nome o crítico apresentava sentidos e explicações inteligentes"'" (HARRISON apud PELED, 2012). E o mais recente deles, "Escritos de Artistas: anos 60/70" organizado por Glória Ferreira e Cecilia Cotrim, no qual os textos 
dos artistas "não só se integram à poética de cada obra, como também invadem o domínio da crítica e da história da arte" (PELED, 2012).

Sem chegar a estabelecer uma categorização de escritos e textos de artistas - o que certamente extrapolaria o escopo deste artigo - podemos perceber que nessa seara há textos que surgem como ramificações do trabalho poético em si. Contudo, uma vez que expandem o universo no qual o artista transita, não se referindo direta ou obviamente ao seu trabalho e tendo estatuto autônomo de criação (seja como ficcionalizações ou ensaios ${ }^{2}$ ), esse tipo de texto parece estar numa condição distinta daquele que se coloca como um lugar de reflexão sobre a própria poética de criação do artista em seus meandros.

Longe de qualquer intenção de se impor regras ou posturas dogmáticas no campo da pesquisa em Poéticas Visuais (o que não faria sentido dada a necessidade que o campo evoca quanto à definição pessoal da própria metodologia a ser seguida por cada artista, como abordarei a seguir), cabe ressaltar que o espírito de se fazer uma pesquisa nessa linha compreende em si o desejo do compartilhamento do conhecimento. O caminho de pesquisa (inevitavelmente claudicante, por vezes até mesmo paradoxal) do artista na articulação do pensamento formal e do pensamento poético implica - como se verifica em qualquer outro campo de pesquisa - dispor para seus leitores e observadores o acompanhamento e o resgate de sua própria caminhada.

Portanto, daí se origina e aí se fundamenta o rigor, a organização e a clareza esperadas na elaboração e na apresentação de uma pesquisa em Poéticas Visuais. Essas exigências fazem parte das formalidades universitárias que se impõe ao artista na elaboração claudicante e de tensão entre os lugares ocupados e transitados pela pesquisa em Poéticas. Nesse aspecto, conforme nos lembra a artista Carla Zaccagnini

\footnotetext{
“Em cada lugar, as coisas se apresentam dentro de certas especificidades. Portanto, o problema não é tanto a universidade dar conta das possibilidades -na verdade, as possibilidades são muito difíceis de determinar, não dá para encerrá-las. Além do mais, acho que em toda apresentação pública de um trabalho artístico você tem normas. Se é num museu, as normas do museu; se é na universidade, as normas da universidade; se é na rua, as normas da Prefeitura. Então, (...) quando você fala do artista
}

driblando ou burlando essas normas, trata-se mais de uma tentativa de expansão, de levar essa norma até o limite, de expandir um pouco esse território que a arte pode ocupar". (RIBEIRO, s.d.).

A despeito das formalidades acadêmicas, o método e a elaboração teórica tem seu princípio baseado em (tanto quanto é possível neste escopo) dar a ver o caminho percorrido pelo artista, em universalizar o conhecimento. Nesse sentido, não se deve deixar de notar a ressalva que aponta o também professor da linha de pesquisa em Poéticas, Yiftah Peled:

Lancri (2002) destaca que a redação do texto que acompanha a pesquisa poética deve buscar a maior precisão possível no pensamento, sem, no entanto, racionalizar a arte. Isso significa situar a produção e não tentar meramente explicá-la, relacionando a teoria e a prática artística. (2012, p. 116).

Ou seja, uma pesquisa em Poéticas Visuais é disposta como um procedimento realmente fértil para o artista quando este manipula a teoria como instrumento e alavanca em seu processo artístico e criativo. Em outras palavras, a universidade e os meandros teóricos colocam-se para os artistas como lugares de reflexão, meditação e autoquestionamento contínuo, no sentido de alavancar seus processos de trabalho, quando eles não se ocupam com uma explicação que teria a pretensão de ser uma espécie de tradução verbal daquilo que o objeto artístico já é por si e em si próprio.

Na articulação teórico-prática de Poéticas, como nos lembra Jean Lancri no mesmo texto que foi citado acima por Peled,

(...) um pesquisador em artes plásticas, a despeito de alguns, utiliza os conceitos. Longe de desdenhálos, ele os usa e os trabalha. Mas ele os trabalha de maneira diferente. Em troca, é diferentemente trabalhado por eles. Por que razões? Porque ele trabalha também (no) o campo do sensível. Um pesquisador em artes plásticas, com efeito, opera sempre, por assim dizer, entre conceituale sensível, entre teoria e prática, entre razão e sonho. (2002, p. 19 , grifo do autor).

De modo que o artista/pesquisador é um pesquisador acadêmico com uma condição bastante particular, pois ele parte já do meio de uma prática própria de trabalho (LANCRI, 2002) para iniciar sua pesquisa. Ao contrário do pesquisador de outras áreas (e mesmo de outras linhas do campo das Artes Visuais), ele próprio inventa seu problema de pesquisa. Se propor a analisá-lo de modo aprofundado e 
sem se fazer concessões é definidor para o que será a continuidade desta prática. O "artista/ pesquisador" assim parte para a "delimitação de seu objeto (ou de seu sujeito) de estudo, o que, de saída, vai condicionar sua estratégia" (Ibid., p. 21), ou seja, a sua metodologia de pesquisa.

Com efeito, dadas as mencionadas particularidades de seu objeto e de seu processo, cada artista/ pesquisador precisa encontrar e moldar sua própria metodologia e seu modo específico de conduzir sua pesquisa teoricamente. Uma vez que

No início de uma pesquisa é comum serem levantadas uma série de questões relacionadas a como a tarefa deve ser abordada. Esse momento de dúvida, comum entre pesquisadores em geral, assume no artista/pesquisador uma dimensão peculiar, pois não está relacionada apenas a aplicação de modelos pré-estabelecidos, mas a fundação de pressupostos metodológicos, que em outras áreas já são de domínio do aluno de graduação. (GONÇALVES, 2009, p. 139).

Para retornar à proposta deste artigo de expor e considerar minha própria prática como artista/ pesquisador no sentido de melhor elucidar as especificidades do que acredito constituir e abarcar uma pesquisa em Poéticas Visuais, chamo a atenção para a mencionada importância da noção de poiética como instrumento teórico. Ao refletir a respeito dos desdobramentos ocorridos na minha própria produção pictórica em ateliê - o que por sua vez auxiliou a continuidade na configuração dessa produção -, a noção de poiética foi encontrada como recurso teórico que fez parte de minha metodologia, e não necessariamente estaria presente na metodologia de outro artista/pesquisador.

Além da poiética, outro conceito empregado por mim naquela metodologia em particular foi o de mestiçagem no contexto da arte contemporânea, tal como é analisado e considerado pela professora e teórica Icleia Cattani. A noção de mestiçagem foi igualmente ferramenta teórica auxiliar ao se considerar uma pesquisa que envolvia a feitura de uma pintura que empregou e integrou meios visuais diversos (cinema, vídeo e fotografia, no caso), mas que não mesclava suas visualidades de modo homogêneo, tampouco trabalhava tais visualidades de modo excludente.

Uma vez que, conforme esclarece Cattani,

Os cruzamentos que suscitam relações com o conceito de mestiçagem são os que acolhem sentidos múltiplos permanecendo em tensão na obra a partir de um princípio de agregação que não visa fundi-los numa totalidade única, mas mantêlos em constante pulsação. Esses cruzamentos tensos são os que constituem as mestiçagens nos processos artísticos atuais. (2007, p. 11).

De modo que as articulações e registros dispostos pelo artista/pesquisador em cada caso procuram "encontrar uma metodologia de trabalho (...) manter o espírito investigativo sistemático (...) ampliando a sensibilidade e a qualidade do processo criativo" (CATTANI, 2002, p. 39).

Assim, enfatiza-se novamente que "a pesquisa de arte buscará o rigor de análise que the permita qualificar-se como pesquisa, aliandoIhe, à sensibilidade do olhar, a profundidade da formação teórica" (Ibid., p. 38, grifo do autor). Com efeito, no decorrer de meu processo criador e de construção pictórica, para constituir a pesquisa e sua metodologia operei incessante emprego de conceitos operatórios, densas análises e ferramentas teóricas auxiliares que provinham de outras áreas de conhecimento, como engrenagens no conjunto de ideias e desenvolvimentos do ateliê.

Este modo de ação e existência do artista através desta linha de pesquisa, para além do universo ensimesmado do artista, justifica-se no campo das Artes Visuais ao se considerar que

(...) só nos é possível pensar a arte através da obra e/ou do artista. (...) A posição de artista/autor pode passar, assim, de suspeita à privilegiada numa pesquisa quando pensamos na arte como uma razão final da reflexão proposta. E tem-se com isso a experiência da prática artística; a obra como condição, com todas as suas contradições. (GONÇALVES, 2009, p. 139).

Aí temos, em poucas linhas, uma definição do lugar que ocupa a pesquisa em Poéticas dentro do campo maior em que se insere. Vale ressaltar e complementar que, como já observado anteriormente, tal definição conceitua especificamente a pesquisa em Poéticas e não tem assim pretensão de abranger o escopo completo dos escritos de artista (que se estende por variações como a do texto como manifesto de um grupo ou ou de um movimento, por exemplo).

Quanto às contradições mencionadas por Gonçalves, volto-me mais uma vez ao exemplo pessoal. Minha tese de doutorado em Poéticas 
Visuais pautou-se pelos paradoxos contidos nas aproximações e junções empreendidas pelo processo prático de trabalho, bem como na constatação de contradições resultantes das mencionadas buscas por rigor e cientificidade numa criação sensível.

O primeiro paradoxo enunciado naquela pesquisa dizia respeito exatamente a esta postura. Entendo que, nesse caso, mesmo a abordagem rigorosa demonstra um descompasso, em seus planejamentos e análises, com os fatos do trabalho, seus resultados e sua potência. O que se evidencia pelo viés do inesperado, do incontrolável, do que escapa à compreensão plena e literal.

A partir daí, assumi tal paradoxo porque a percepção foi a de que, a partir da rebuscada tessitura presente na metodologia proposta, criaram-se as condições possíveis e necessárias para que o trabalho acontecesse. Em outras palavras, essa elaboração metodológica particular revelou-se requisito para que o trabalho prático surgisse, fazendo com que este ganhasse autonomia própria em relação à metodologia e preceitos traçados que o originaram. Acredito também que "lidar com o arcabouço metodológico poderá permitir que a invenção e a fruição convivam com a clareza e o rigor, necessários à produção e à transmissão de conhecimento" (CATTANI, 2002, p. 49). Ademais, essa busca metodológica sistemática ecoou as organizações de como se dava a feitura em ateliê dos processos práticos da pesquisa.

Procurei enfatizar naquela pesquisa, portanto, que a condição primordial da elaboração textual era a de ser colocada em trabalho com a pintura, com os propósitos de refletir sobre essa execução e, simultaneamente, analisar essa feitura em profundidade, através de um processo de distanciamento do ato criador, a despeito do quão errante e repleto de bifurcações tal percurso possa ser. Cabe esclarecer que ao mencionar distanciamento nesse contexto o faço no mesmo sentido que indica Gonçalves, ao considerar que

O artista/pesquisador se coloca como um observador implicado em seu objeto, com o dever de dele distanciar-se o suficiente para criar "espaço" para a observação e a interpretação, num vai e vem semelhante ao que exercita quando da fatura do seu trabalho. Esse espaço é tencionado pela rememoração da experiência, pela autocrítica e, por conseguinte, pela invenção. (GONÇALVES, 2009, p. 139).
Ou seja, como menciona Jean Lancri, situar-se nessa distância que procura racionalizar aquilo que é da esfera do sonho (2002). Postura descrita por Gerhard Richter como artista e pintor, em um texto seu de 1966:

Este é o estado de modesta sabedoria que nos permite transcender a nós mesmos, no sentido de fazer algo que não conseguimos apreender com nossa inteligência mas somente entender e admirar em nossos corações. Porém, não quero com isso dizer que tal atitude tenha qualquer relação com passividade. (RICHTER, 1995, p.49). ${ }^{3}$

Ao longo do período que compreendeu a elaboração daquela pesquisa, a intenção foi a de se trabalhar com este cuidado metodológico, visando uma autonomia da pintura em sua feitura, em sua execução e acontecimento próprios. Trata-se de uma postura que desejava deixar a pintura acontecer pelos seus próprios meandros de instauração, imprevisíveis para o pintor. 0 acontecimento-pintura depende, portanto, dessa negociação constante entre os desígnios do pintor e a autonomia pictórica.

De todo modo, mesmo que o conjunto de escolhas de trabalho tenha ocorrido em certa medida, e inerentemente, de forma intuitiva, suas ações foram fertilizadas a partir das condições instauradas no direcionamento, especificidades e repertório decorrentes do desenvolvimento daquela pesquisa em Poéticas Visuais. Nota-se aí o imbricamento e trânsito entre teoria e prática em Poéticas, dado que aquela pesquisa, por sua vez, se deu através da consideração de maneira sistemática das reflexões, registros e estudos teóricos elaborados conjuntamente à prática em ateliê.

Foram abordados, em diversos momentos no texto da pesquisa, campos distintos e eventualmente distantes da Arte (tais como sociologia e filosofia, por exemplo). Mas deve ser ressaltado que estes foram considerados sempre pela ótica e viés específicos do problema instaurado pela pesquisa.

Aí reside outro aspecto que delineia a pesquisa em Poéticas, e que podemos chamar de "fio condutor". Uma vez que este tipo de pesquisa tem como objetivo principal debruçar-se sobre o processo de criação, são as exigências e as demandas desse processo que acabam por nortear suas reflexões (mesmo que algumas dessas reflexões instaurem-se como desvios ou apêndices a partir 
do processo - e nesse contexto a expressão "a partir de" é chave). É este norte que chamo aqui de "fio condutor", e que pode nos ajudar a visualizar a relevância dos desenvolvimentos que vão sendo dispostos ao longo da elaboração da pesquisa.

Os fragmentos destacados e correlacionados entre si nas páginas do volume escrito, resultante da pesquisa, apontaram situações, elucidaram conceitos e noções e, até mesmo, aprofundaram dúvidas incontornáveis no decorrer daquele percurso. Assim, no momento de encerramento daquela pesquisa empreendi uma apreciação e recapitulação de todo o trabalho e das tessituras empreendidas ao longo de sua construção.

Ao se alcançar aquele momento de maturidade daquela pintura, alcançou-se também uma compreensão dela que incitava sua própria continuidade, sem que esta se esgotasse - na verdade, o que se evocava era exatamente o oposto de qualquer esgotamento. Contudo, isto não significa que houvesse qualquer segurança ou previsibilidade nesta continuidade. Nesse sentido, a sensação parece ser semelhante àquela manifestada por Gerhard Richter, quando o pintor alude ao permanente enigma que constitui o ato pictórico:

\begin{abstract}
Richter nunca deu lugar à tentação de pensar que pudesse ser possível planejar o resultado de sua pintura, ou controlar sua execução. Seus apontamentos contêm muitas observações do modo como, ao alcançar certo estágio, ele teve que "destruir" ou "salvar" um trabalho. No processo de criação, os quadros desenvolvem uma dinâmica própria que frequentemente surpreendem o próprio artista, e mesmo que ele possa intervir para fazer correções, nunca está totalmente no domínio desta. "Levou um bom tempo", Gerhard Richter finalmente admite para si próprio, "até que eu me desse conta de que o que eu faço - a experimentação desesperada, todo o conjunto de dificuldades - é exatamente o que todos eles fazem: esta é a natureza do trabalho. Isto é pintura. (ELGER, 2001, p. 109-110). ${ }^{4}$
\end{abstract}

Procurei igualmente alcançar ao longo das páginas de todo volume de minha tese um entendimento da elaboração e discussão teórica como elemento motor deste tipo de pesquisa. Essa é a experiência que busco compartilhar neste artigo, ao menos tanto quanto é possível nesse sentido. Posto que ao fim daquele caminho ficou claro para mim que o ato de fazer pesquisa em artes contempla, em última instância, apreender e descobrir aquilo que é e que configura a própria pesquisa em Poéticas Visuais.

\section{NOTAS}

1. "O chamado "artista/pesquisador" revela em sua designação a fronteira que constitui seu território, entre a prática artística e o pensamento formal". (GONÇALVES, 2009, p. 139).

2. Como exemplo disto, e tomando aqui a minha própria experiência com pesquisa e tessituras teóricas referenciais utilizadas como artista/ pesquisador, temos os textos compilados no livro "Collected Writings" de Richard Prince (2011), nos quais o artista imagina situações e personagens fictícios quase como um romancista.

3. Livre tradução de : "This is the state of modest wisdom that allows us to transcend ourselves, to do something that we can't grasp with our intelligence but only understand and admire in our hearts. I don't mean that this has anything to do with passivity".

4. Livre tradução de: "Richter has never given way to the temptation of thinking it possible to plan the outcome of his painting or control its execution. His notes contain many accounts of the way in which, on reaching a certain stage, he has to "destroy" or "save" a work. In the process of creation, the pictures develop a dynamic of their own which often amazes the artist himself, and while he may intervene to make corrections he is never entirely in charge of it. "It was a long time", Gerhard Richter finally admitted to himself, "before I realized that what I do - the desperate experimentation, all the difficulties - is exactly what they all do: that's the normal nature of the job. That's painting".

\section{REFERÊNCIAS}

CATTANI, Icleia Borsa. "Arte Contemporânea: O lugar da pesquisa". In: BRITES, Blanca; TESSLER, Elida (Org.). 0 Meio Ponto Zero: Metodologia da Pesquisa em Artes Plásticas. Porto Alegre: Editora da UFRGS, 2002.

(Org.). Mestiçagens na

Arte Contemporânea. Porto Alegre: Editora da UFRGS, 2007. 
CHIPP, Herschel B. Teorias da Arte Moderna. São Paulo: Martins Fontes, 1988.

ELGER, Dietmar. "Failure as an Artistic Agenda: The Paintings of Gerhard Richter". In:

Warhol, Polke, Richter: In the Power of

Painting 1. Londres: Thames and Hudson, 2001

FERREIRA, Glória; COTRIM, Cecilia. (Org.). Escritos de Artistas: anos 60/70. Rio de Janeiro: Jorge Zahar, 2006.

GONÇALVES, Flávio. "Um argumento frágil". In: Porto Arte, Porto Alegre: Instituto de Artes/ UFRGS, v.16 n.27, nov. 2009.

HARRISON, Charles; WOOD, Paul. Art in theory, 1900-2000: an anthology of changing ideas. Londres: Blackwell Publishing, 2003.

LANCRI, Jean. "Modestas proposições sobre as condições de uma pesquisa em artes plásticas na Universidade". In: BRITES, Blanca; TESSLER, Elida (Org.). 0 Meio como Ponto Zero: Metodologia de Pesquisa em Artes Plásticas. Porto Alegre: Editora da UFRGS, 2002.

PASSERON, René. "A poiética em questão". In: Porto Arte, Porto Alegre: Instituto de Artes/ UFRGS, v.13 n.21, jul. 2004.

PELED, Yiftah. "Metodologia em Poéticas Visuais". In: Porto Arte, Porto Alegre: Instituto de Artes/ UFRGS, v.19 n.33, nov. 2012.

PRINCE, Richard. Collected Writing. Nova York: Foggy Notion Books, 2011.

RIBEIRO, José Augusto. Arte e Universidade: como foi o Encontro Trópico na Pinacoteca. Dossiê Debate/Em Obras. s.d. Disponível em: <http://p.php.uol.com.br/tropico/html/ textos/2378,1.shl>. Acesso em: 23 junho 2015.

RICHTER, Gerhard. "Text for exhibition catalogue, Galerie h, Hanover, 1966". In: OBRIST, Hans-Ulrich (Ed.). The Daily Practice of Painting: Writtings 1962-1993. Cambridge: The MIT Press, 1995

WOOD, Paul. Arte Conceitual. São Paulo: Cosac \& Naify, 2002. (Movimentos da Arte moderna).
Pesquisador Pós-doutoral no PPGARTES da Universidade Federal do Pará (UFPA). Doutor (2013) e Mestre (2008) em Artes Visuais (ênfase em Poéticas Visuais) pelo PPG em Artes Visuais da Universidade Federal do Rio Grande do Sul, UFRGS, possui graduação em Artes Visuais - habilitação Design Gráfico pela Universidade Federal de Pelotas, UFPel (2003). Atualmente trabalha como professor adjunto na área de Fundamentos da Linguagem Visual no Centro de Artes da UFPel. É membro fundador do Coletivo C.D.M. (Centro de Desintoxicação Midiática). Tem experiência na área de Artes Visuais, com ênfase em Pintura, atuando principalmente nos seguintes temas: arte contemporânea, pintura, fundamentos da linguagem visual, composição visual, fotografia, história da arte. Realizou exposições individuais e coletivas em Rio Grande do Sul, Santa Catarina, Paraná, Minas Gerais, Rio de Janeiro, São Paulo e Brasília. Participou da $7^{\text {a }}$ Bienal de Artes Visuais do Mercosul. Endereço eletrônico: http://www.ricardomello.org

Sobre 0 autor 